Kong. Res. J. 2(2) : 23-25, 2015

Kongunadu Arts and Science College, Coimbatore.

\title{
COMPLETELY SUPRA N-CONTINUOUS FUNCTION
}

\section{Vidyarani, $L^{*}$. and M. Vigneshwaran}

Department of Mathematics, Kongunadu Arts and Science College (Autonomous), Coimbatore.

*E.mail: vidyarani16@gmail.com

\section{ABSTRACT}

In this paper, we introduce a new concept called completely supra $\mathrm{N}$-continuous function and investigated its relationship with other functions.

Keywords: Completely supra N-continuous function.

\section{INTRODUCTION}

The notion of supra topological spaces, scontinuous functions and $\mathrm{s}^{*}$-continuous functions was introduced (Mashhour et al, 1983). Supra Nclosed set was introduced and supra N-continuity and supra $\mathrm{N}$-irresoluteness investigated (Vidyarani and Vigneshwaran, 2013a).

In this paper, we introduce the concept of completely supra $\mathrm{N}$-continuous function and investigated its relationship with other functions in supra topological space.

\section{PRELIMINARIES}

\subsection{Definition}

A subfamily $\mu$ of $X$ is said to be supra topology on X if

i) $X, \phi \in \mu$

ii) If $A_{i} \in \mu \forall i \in j$ then $\cup A_{i} \in \mu$. (X, $\left.\mu\right)$ is called supra topological space.

The element of $\mu$ are called supra open sets in $(X, \mu)$ and the complement of supra open set is called supra closed sets and it is denoted by $\mu^{\mathrm{c}}$.

\subsection{Definition}

The supra closure of a set $A$ is denoted by $\mathrm{cl}^{\mu}(\mathrm{A})$, and is defined as supra $\operatorname{cl}(\mathrm{A})=\cap\{\mathrm{B}: \mathrm{B}$ is supra closed and $\mathrm{A} \subseteq \mathrm{B}\}$.

The supra interior of a set $A$ is denoted by $\operatorname{int}^{\mu}(A)$, and is defined as supra $\operatorname{int}(A)=U\{B: B$ is supra open and $\mathrm{A} \supseteq \mathrm{B}$ \}.

\subsection{Definition}

Let $(X, \tau)$ be a topological space and $\mu$ be a supra topology on $\mathrm{X}$. We call $\mu$ a supra topology associated with $\tau$, if $\tau \subseteq \mu$.

\subsection{Definition}

Let $(X, \mu)$ be a supra topological space. A set $A$ of $X$ is called

(i) supra semi- open set (Levine, 1991), if $A \subseteq$ ${ }_{\mathrm{cl}^{\mu}}^{\mu}\left(\right.$ int $\left.^{\mu}(\mathrm{A})\right)$.

(ii) supra $\alpha$-open set (Devi et al., 2008), if $A \subseteq$ int $\left.^{\mu}\left(\mathrm{cl}^{\mu}{ }_{\left(\text {int }^{\mu}\right.}{ }^{\mu}(\mathrm{A})\right)\right)$.

(iii) supra $\Omega$ closed set (Noiri and Sayed, 2005), if $\operatorname{scl}^{\mu}(\mathrm{A}) \subseteq$ int $^{\mu}(\mathrm{U})$, whenever $\mathrm{A} \subseteq \mathrm{U}, \mathrm{U}$ is supra open set.

(iv) supra $\mathrm{N}$-closed set (Vidyarani and Vigneshwaran, 2013a), if $\Omega \mathrm{cl}^{\mu}(\mathrm{A}) \subseteq \mathrm{U}$, whenever $\mathrm{A} \subseteq \mathrm{U}, \mathrm{U}$ is supra $\alpha$ open set.

The complement of above supra closed set is supra open and vice versa.

\subsection{Definition}

$$
\text { A map } \mathrm{f:}(\mathrm{X}, \tau) \rightarrow(\mathrm{Y}, \sigma) \text { is said to be }
$$

(i) supra $\mathrm{N}$-continuous (Vidyarani and Vigneshwaran, 2013b), if $\mathrm{f}^{-1}(\mathrm{~V})$ is supra $\mathrm{N}$ closed in $(X, \tau)$ for every supra closed set $V$ of $(Y, \sigma)$.

(ii) Supra N-irresolute (Vidyarani and Vigneshwaran, 2013a), if $\mathrm{f}^{-1}(\mathrm{~V})$ is supra $\mathrm{N}$ closed in $(X, \tau)$ for every supra $N$ - closed set $\mathrm{V}$ of $(\mathrm{Y}, \sigma)$.

(iii) strongly supra $\mathrm{N}$-continuous (Vidyarani and Vigneshwaran, 2013b), if $\mathrm{f}^{-1}(\mathrm{~V})$ is supra closed in $(X, \tau)$ for every supra $N$-closed set $\mathrm{V}$ of $(\mathrm{Y}, \sigma)$. 


\section{COMPLETELY SUPRA N-CONTINUOUS FUNCTIONS}

\subsection{Definition}

A map $\mathrm{f}:(\mathrm{X}, \tau) \rightarrow(\mathrm{Y}, \sigma)$ is called completely supra continuous function, if $\mathrm{f}^{-1}(\mathrm{~V})$ is supra Regular closed in $(X, \tau)$ for every supra closed set $\mathrm{V}$ of $(\mathrm{Y}, \sigma)$.

\subsection{Definition}

A map $\mathrm{f}:(\mathrm{X}, \tau) \rightarrow(\mathrm{Y}, \sigma)$ is called completely supra $\mathrm{N}$-continuous function, if $\mathrm{f}^{-1}(\mathrm{~V})$ is supra Regular closed in $(X, \tau)$ for every supra $\mathrm{N}$ - closed set $\mathrm{V}$ of $(\mathrm{Y}, \sigma)$.

\subsection{Theorem}

Every completely supra $\mathrm{N}$-continuous function is completely supra continuous function.

Proof Let $\mathrm{f}:(\mathrm{X}, \tau) \rightarrow(\mathrm{Y}, \sigma)$ be a completely supra $\mathrm{N}$-continuous function. Let $\mathrm{V}$ be supra closed set in $(Y, \sigma)$. Then $V$ is supra $N$-closed set in $(Y, \sigma)$, since every supra closed set is supra $\mathrm{N}$-closed set. Since $\mathrm{f}$ is completely supra $\mathrm{N}$-continuous function, then $\mathrm{f}^{-1}(\mathrm{~V})$ is supra regular closed in $(\mathrm{X}, \tau)$. Therefore $\mathrm{f}$ is completely supra continuous function.

The converse of the above theorem need not be true. It is shown by the following example.

\subsection{Example}

Let $\mathrm{X}=\mathrm{Y}=\{\mathrm{a}, \mathrm{b}, \mathrm{c}\}$ and $\tau=\{\mathrm{X}, \varphi,\{\mathrm{a}\},\{\mathrm{b}, \mathrm{c}\}\}, \sigma$ $=\{\mathrm{Y}, \varphi,\{\mathrm{a}\}\}$. Let $\mathrm{f}:(\mathrm{X}, \tau) \rightarrow(\mathrm{Y}, \sigma)$ be the function defined by $f(a)=a, f(b)=c, f(c)=b$. Here $f$ is completely supra continuous but not compl etely supra $\mathrm{N}$-continuous, since $\mathrm{V}=\{\mathrm{a}, \mathrm{c}\}$ is s u p r a N - closed in $(Y, \sigma)$ but $f^{-1}(\{a, c\})=\{a, b\}$ is not supra regular closed set in $(X, \tau)$.

\subsection{Theorem}

Every compl etely supra $\mathrm{N}$-continuous function is supra $\mathrm{N}$-continuous function.

Proof Let $\mathrm{f:}(\mathrm{X}, \tau) \rightarrow(\mathrm{Y}, \sigma)$ be a compl etely supra $\mathrm{N}$-continuous function. Let $\mathrm{V}$ be supra closed set in $(\mathrm{Y}, \sigma)$. Then $\mathrm{V}$ is supra $\mathrm{N}$-closed set in $(Y, \sigma)$, since every supra closed set is supra $\mathrm{N}$ closed set. Since $\mathrm{f}$ is completely supra $\mathrm{N}$-continuous function, then $f^{-1}(V)$ is supra regular closed in $(X, \tau)$. Since every supra regular closed set is supra closed set and every supra closed set is supra $\mathrm{N}$-closed set, then $f^{-1}(V)$ is supra $N$-closed in $(X, \tau)$. Therefore $f$ is supra $\mathrm{N}$-continuous function.

The converse of the above theorem need not be true. It is shown by the following example.

\subsection{Example}

Let $\mathrm{X}=\mathrm{Y}=\{\mathrm{a}, \mathrm{b}, \mathrm{c}\}$ and $\tau=\{\mathrm{X}, \varphi,\{\mathrm{a}\},\{\mathrm{b}, \mathrm{c}\}\}, \sigma$ $=\{Y, \varphi,\{a\}\}$. Let $f:(X, \tau) \rightarrow(Y, \sigma)$ be the function defined by $f(a)=b, f(b)=c, f(c)=a$. Here $f$ is supra $\mathrm{N}$-continuous but not completely supra $\mathrm{N}$ continuous, since $\mathrm{V}=\{\mathrm{a}, \mathrm{c}\}$ is $\mathrm{s} \mathrm{u} \mathrm{p} \mathrm{r}$ a $\mathrm{N}$ - closed in $(Y, \sigma)$ but $f^{-1}(\{a, c\})=\{a, b\}$ is not suprareg ular closed set in $(X, \tau)$.

\subsection{Theorem}

Every compl etely supra $\mathrm{N}$-continuous function is supra $\mathrm{N}$-irresolute function.

Proof Let $\mathrm{f}:(\mathrm{X}, \tau) \rightarrow(\mathrm{Y}, \sigma)$ be a compl etely supra $\mathrm{N}$-continuous function. Let $\mathrm{V}$ be supra $\mathrm{N}$-closed set in $(\mathrm{Y}, \sigma)$. Since $\mathrm{f}$ is completely supra $\mathrm{N}$-continuous function, then $\mathrm{f}^{-1}(\mathrm{~V})$ is supra regular closed in $(X, \tau)$. Since every supra regular closed set is supra closed set and every supra closed set is supra $\mathrm{N}$-closed set, then $\mathrm{f}^{-1}(\mathrm{~V})$ is supra $\mathrm{N}$ closed in $(X, \tau)$. Therefore $f$ is supra $\mathrm{N}$-irresolute function.

The converse of the above theorem need not be true. It is shown by the following example.

\subsection{Example}

Let $\mathrm{X}=\mathrm{Y}=\{\mathrm{a}, \mathrm{b}, \mathrm{c}\}$ and $\tau=\{\mathrm{X}, \varphi,\{\mathrm{a}\},\{\mathrm{b}, \mathrm{c}\}\}, \sigma$ $=\{\mathrm{Y}, \varphi,\{\mathrm{a}\}\}$. Let $\mathrm{f}:(\mathrm{X}, \tau) \rightarrow(\mathrm{Y}, \sigma)$ be the function defined by $f(a)=b, f(b)=c, f(c)=a$. Here $f$ is supra $\mathrm{N}$-irresolute but not compl etely supra $\mathrm{N}$ continuous, since $V=\{a, c\}$ is $s \mathrm{u} p \mathrm{r}$ a $\mathrm{N}$ - closed in $(Y, \sigma)$ but $f^{-1}(\{a, c\})=\{a, b\}$ is not supra regular closed set i n $(X, \tau)$.

\subsection{Theorem}

Every compl etely supra $\mathrm{N}$-continuous function is strongly supra $\mathrm{N}$-continuous function.

Proof Let $\mathrm{f}:(\mathrm{X}, \tau) \rightarrow(\mathrm{Y}, \sigma)$ be a compl etely supra $\mathrm{N}$-continuous function. Let $\mathrm{V}$ be supra $\mathrm{N}$-closed set in $(\mathrm{Y}, \sigma)$. Since $\mathrm{f}$ is completely supra $\mathrm{N}$-continuous function, then $\mathrm{f}^{-1}(\mathrm{~V})$ is supra regular closed in $(X, \tau)$. Since every supra regular closed set is supra closed set, then $\mathrm{f}^{-1}(\mathrm{~V})$ is supra closed in $(X, \tau)$. Therefore $f$ is strongly supra $N$ continuous function.

The converse of the above theorem need not be true. It is shown by the following example.

\subsection{Example}

Let $\mathrm{X}=\mathrm{Y}=\{\mathrm{a}, \mathrm{b}, \mathrm{c}\}$ and $\tau=\{\mathrm{X}, \varphi$, $\{a\},\{b\},\{a, b\},\{b, c\}\}, \sigma=\{Y, \varphi,\{a, b\},\{b, c\}\}$. Let $f:(X, \tau)$ $\rightarrow(\mathrm{Y}, \sigma)$ be the function defined by $\mathrm{f}(\mathrm{a})=\mathrm{a}$, $f(b)=c, \quad f(c)=b$. Here $f$ is strongly supra N- 
continuous but not compl etely supra $\mathrm{N}$ continuous, since $\mathrm{V}=\{\mathrm{a}, \mathrm{c}\}$ is $\mathrm{s} \mathrm{u}$ p r a N - closed in $(Y, \sigma)$ but $^{-1}(\{a, c\})=\{a, b\}$ is not supra regular closed set i $n(X, \tau)$.

\subsection{Remark}

Composition of two completely supra Ncontinuous function is completely supra $\mathrm{N}$ continuous

\subsection{Theorem}

If $\mathrm{f}:(\mathrm{X}, \tau) \rightarrow(\mathrm{Y}, \sigma)$ is supra $\mathrm{N}$-continuous and $\mathrm{g}:(\mathrm{Y}, \sigma) \rightarrow(\mathrm{Z}, \eta)$ is completely supra $\mathrm{N}$-continuous then gof: $(X, \tau) \rightarrow(Z, \eta)$ is supra $N$-irresolute.

Proof Let $\mathrm{V}$ be supra $\mathrm{N}$-closed set in $\mathrm{Z}$. Since $\mathrm{g}$ is completely supra N-continuous, then $\mathrm{g}$ ${ }^{1}(\mathrm{~V})$ is supra regular closed set in Y. Since every supra regular closed set is supra closed set, $g^{-1}(V)$ is supra closed set in Y. Since $\mathrm{f}$ is supra N-continuous, then $f^{-1} g^{-1}(V)$ is supra $N$-closed in $X$. Hence gof is supra $\mathrm{N}$-irresolute.

\subsection{Theorem}

If $\mathrm{f}:(\mathrm{X}, \tau) \rightarrow(\mathrm{Y}, \sigma)$ is completely supra $\mathrm{N}$ continuous and $\mathrm{g}:(\mathrm{Y}, \sigma) \rightarrow(\mathrm{Z}, \eta)$ is supra $\mathrm{N}$ continuous then gof: $(X, \tau) \rightarrow(Z, \eta)$ is completely supra continuous.

Proof Let V be supra closed set in Z. Since $g$ is supra $\mathrm{N}$-continuous, then $\mathrm{g}^{-1}(\mathrm{~V})$ is supra $\mathrm{N}$-closed set in $\mathrm{Y}$. Since $\mathrm{f}$ is completely supra N-continuous, then $\mathrm{f}^{-1} \mathrm{~g}^{-1}(\mathrm{~V})$ is supra regular closed set in $\mathrm{X}$. Hence gof is completely supra $\mathrm{N}$-continuous.

\subsection{Theorem}

If $\mathrm{f}:(\mathrm{X}, \tau) \rightarrow(\mathrm{Y}, \sigma)$ is strongly supra $\mathrm{N}$ continuous and $\mathrm{g}:(\mathrm{Y}, \sigma) \rightarrow(\mathrm{Z}, \eta)$ is completely supra $\mathrm{N}$-continuous then gof: $(X, \tau) \rightarrow(Z, \eta)$ is strongly supra continuous.
Proof Let $\mathrm{V}$ be supra $\mathrm{N}$-closed set in $\mathrm{Z}$. Since $g$ is completely supra N-continuous, then $\mathrm{g}$ ${ }^{1}(\mathrm{~V})$ is supra regular closed set in Y. Since every supra regular closed set is supra closed set and every supra closed set is supra $\mathrm{N}$-closed set, $\mathrm{g}^{-1}(\mathrm{~V})$ is supra $\mathrm{N}$-closed set in Y. Since f is strongly supra $\mathrm{N}$ continuous, then $\mathrm{f}^{-1} \mathrm{~g}^{-1}(\mathrm{~V})$ is supra closed set in $\mathrm{X}$. Hence gof is strongly supra $\mathrm{N}$-continuous.

\subsection{Remark}

The following implications is obtained from the above theorems

Completely supra $\mathrm{N}$-continuous $\rightarrow$ strongly supra N-continuous $\rightarrow$ supra $\mathrm{N}$-irresolute $\rightarrow$ supra $\mathrm{N}$ continuous

\section{REFERENCES}

Devi, R., S. Sampathkumar and M. Caldas, (2008). On supra $\alpha$ open sets and $s \alpha$-continuous maps. General Math., 16(2): 77-84.

Levine, N. (1991). Semi-open sets and Semicontinuity in topological spaces. Amer. Math., 12: 5-13.

Mashhour, A.S., A.A. Allam, F.S. Mahmoud and F.H. Khedr, (1983). On supra topological spaces. Indian J. Pure Appl. Math.,14(A): 502-510.

Noiri, T. and O.R. Sayed, (2005). On $\Omega$ closed sets and $\Omega$ s closed sets in topological spaces. Acta. Math., 4: 307-318.

Vidyarani, L. and M. Vigneshwaran, (2013a). NHomeomorphism and $\mathrm{N}^{*}$-Homeomorphism in supra topological spaces. Int. J. Math. Stat. Inven., 1(2): 79-83.

Vidyarani, L. and M. Vigneshwaran, (2013b). On supra $\mathrm{N}$-closed and $\mathrm{sN}$-closed sets in supra Topological spaces. Int. J. Math. Arch., 4(2): 255259 